\title{
Afetividade, ensino e aprendizagem: um estudo no GT20 da ANPEd
}

\author{
Elvira Cristina Martins Tassoni \\ Angélica Niero Mendes dos Santos
}

\begin{abstract}
Resumo
Este artigo traz um levantamento bibliográfico dos trabalhos apresentados no GT20 - Psicologia da Educação da ANPEd (Associação Nacional de Pós-Graduação e Pesquisa em Educação) no período de 2000 a 2010. O objetivo foi rastrear as produções científicas mais recentes que discutem a afetividade e sua relação com os processos de ensino e aprendizagem. Apresenta as perspectivas teóricas em que os estudos sobre a afetividade foram abordados e em que medida tais estudos discutem as influências entre os aspectos afetivos e os processos de ensino e aprendizagem. Os trabalhos foram selecionados segundo os procedimentos metodológicos da análise de conteúdo fundamentada em Bardin (1977). Os resultados permitiram a construção de um panorama a respeito dos estudos sobre afetividade, apontando tendências, períodos em que as discussões sobre o tema foram mais intensas e, sobretudo, demonstrando que tal temática vem marcando presença constante nas discussões das Reuniões Anuais da ANPEd.
\end{abstract}

Palavras-chave: Emoções, aprendizagem, psicologia educacional.

\section{Affection, teaching and learning: a study at ANPEd's GT20}

\begin{abstract}
In this paper we offer a bibliographical survey of the papers presented at GT20 - Educational Psychology of ANPEd (AssociaçãoNacional de PósGraduação e PesquisaemEducação - National Association of Post-Graduation and Research in Education) from 2000 to 2010 . The aim is to track the most recent scientific studies which discuss the affection and its relation to the teaching and learning processes. We present the theoretical perspectives in which the studies about affection were addressed and the extents to which such studies discuss the influences between the affective aspects and the teaching and learning processes. The papers were selected according to the methodological procedures of the content analysis based on Bardin (1977). The results allowed constructing an overview of affection studies, pointing tendencies out, periods in which the discussions on the theme were more intense and, above all, demonstrating that such an issue has been more and more raised in discussions of ANPEd's Annual Meetings.
\end{abstract}

Keywords: Emotions, learning, educational psychology.

\section{Afectividad, enseñanza y aprendizaje: un estudio en el GT20 de la ANPEd}

\section{Resumen}

Este artículo presenta una revisión bibliográfica de los trabajos presentados en el GT20 - Psicología de la Educación de la ANPEd (Asociación Nacional de Post-Grado e Pesquisa en Educación) en el período de 2000 a 2010. El objetivo fue rastrear las producciones científicas más recientes que discuten la afectividad y su relación con los procesos de enseñanza y aprendizaje. Presenta las perspectivas teóricas de los estudios sobre la afectividad y en qué medida tales estudios discuten las influencias entre los aspectos afectivos y los procesos de enseñanza y aprendizaje. Los trabajos fueron seleccionados según los procedimientos metodológicos del análisis de contenido fundamentado en Bardin (1977). Los resultados permitieron una visión general de los estudios sobre afectividad indicando tendencias, períodos en que las discusiones sobre el tema fueron más intensas y sobretodo demostrando que este tema está presente de forma constante en las discusiones de las Reuniones Anuales de la ANPEd. Palabras clave: Emociones, aprendizaje, psicología educacional. 


\section{Introdução}

Nos últimos anos tem se observado um crescimento de pesquisas sobre a afetividade. Identificar as abordagens teóricas nas quais esses estudos vêm se pautando contribui para a compreensão desse fenômeno. Além disso, pesquisar sobre a afetividade na escola, compreendendo que na dinâmica da sala de aula circulam conhecimentos e sentimentos, constitui-se aspecto essencial para a reflexão das práticas pedagógicas e para a formação do professor. Foi pensando em construir um panorama sobre esses estudos que este artigo apresenta o resultado de uma pesquisa bibliográfica que teve por objetivo rastrear as produções científicas atuais que discutem a questão da afetividade e a sua relação com os processos de ensino e aprendizagem no GT20 - Psicologia da Educação - da ANPEd (Associação Nacional de Pós-Graduação e Pesquisa em Educação) no período de 2000 a 2010.

A opção pela ANPEd justifica-se por ser a associação científica mais antiga e de muito prestígio na área da Educação no Brasil. É um importante fórum de debates das questões científicas e políticas no âmbito educacional e se constitui num evento que reúne, anualmente, docentes dos Programas de Pós-Graduação de todo o país. Tem como principais objetivos desenvolver e consolidar o ensino de pós-graduação e a pesquisa na área da Educação. As Reuniões Anuais da ANPEd têm tornado-se referência para o acompanhamento da produção científica no campo educacional.

A ANPEd está dividida em áreas temáticas organizadas em diferentes Grupos de Trabalho (GTs). Atualmente existem 23 GTs que promovem a discussão de temas e de pesquisas de fundamental relevância à Educação'. A pesquisa concentrou-se no GT20 - Psicologia da Educação, por sua aproximação com o objeto de estudo em questão - a afetividade.

O GT Psicologia da Educação surgiu no ano de 1999, após ter funcionado dois anos antes na condição de Grupo de Estudo (GE). Como GE de Psicologia da Educação, recebeu inúmeras inscrições de trabalhos e contou com a presença de uma expressiva parcela de pesquisadores do país, o que garantiu a constituição do GT20 na ANPEd, garantindo um espaço para "refletir sobre a relação entre a Psicologia e a Educação, em particular quanto aos aspectos históricos, epistemológicos e metodológicos da pesquisa educacional" (Silva \& Peixoto, 2000, p.10).

O recorte temporal entre 2000 e 2010 ocorreu em razão de ter sido somente após o ano 2000 que os trabalhos apresentados tornaram-se disponíveis para acesso on-line no site da ANPEd. O limite 2010 aconteceu em função do período de realização da pesquisa.

$\mathrm{Na}$ ANPEd são apresentadas algumas modalidades de trabalhos. Os pôsteres referem-se às pesquisas que estão em andamento; os trabalhos são as apresentações realizadas no formato de comunicação oral e contemplam "os

1 Para mais informações sobre cada GT, acesse: http:Ilwww. anped.org.br ensaios (distintos de revisão de literatura) e os estudos com conclusão parciais ou finais, abordando temáticas novas ou já estabelecidas na área da Educação, que evidenciem elaboração teórica e rigor conceitual na análise" (http://www. anped.org.br/); os minicursos são propostas de atividades desenvolvidas para um trabalho de dois dias e têm estreita ligação com o tema do GT ao qual será submetido; os trabalhos encomendados são solicitações feitas aos pesquisadores, que enfatizam temáticas relevantes ao GT em que serão apresentados; as sessões especiais são solicitações que podem discutir tanto o tema central da Reunião Anual, como temas de interesse de um conjunto de GTs.

Segundo informações encontradas no site oficial da ANPEd, os pôsteres, trabalhos e minicursos são submetidos à Comissão Científica e sujeitos à aprovação. Já os trabalhos encomendados e sessões especiais são produções elaboradas a partir de solicitações feitas pelos coordenadores dos GTs e pela diretoria da ANPEd com a colaboração do Fórum de Coordenadores de Programas de Pós-Graduação em Educação (FORPRED).

A pesquisa realizada fundamenta-se numa abordagem qualitativa de investigação, cuja técnica de análise e interpretação dos dados adotada foi a análise de conteúdo qualitativa aplicada aos trabalhos completos de pesquisa científica apresentados no GT20 Psicologia da Educação.

A busca pelos dados para a constituição do estudo deu-se a partir de duas questões norteadoras: em que perspectivas teóricas os estudos sobre a afetividade têm sido abordados e discutidos? E em que medida tais estudos contemplam as influências dos aspectos afetivos nos processos de ensino e aprendizagem?

A seguir, apresenta-se cada etapa dos procedimentos de busca realizados, explicitando os resultados encontrados em tabelas, seguidas de reflexões acerca do tema.

\section{O caminho percorrido}

Após uma exploração detalhada do site da ANPEd, iniciou-se o mapeamento dos dados que interessavam à pesquisa. A coleta e organização das informações fundamentaram-se em Bardin (1977). A autora sugere três etapas de trabalho para o estudo bibliográfico: a pré-análise; a exploração do material coletado; e o tratamento das informações obtidas, a inferência e a interpretação.

A pré-análise consistiu no momento inicial de organização de procedimentos de busca por meio de palavras-chave que possibilitaram rastrear as produções a serem submetidas à análise. Segundo Bardin (1977), é o momento de elaboração de indicadores e de regras para a realização dos recortes necessários, constituindo-se assim o corpus da pesquisa. É, portanto, o momento de preparação do material a ser explorado.

A identificação das produções foi feita a partir das seguintes palavras-chave presentes nos títulos: afetividade; subjetividade; processo ensino-aprendizagem; sentimentos e emoções; mediação pedagógica; psicologia e/da educa- 
ção; sucesso/insucesso escolar; fracasso escolar; relação professor-aluno.

Algumas variações no uso das palavras-chave foram contempladas, como Psicologia Educacional ao invés de Psicologia da Educação e subjetivação como uma variação para o termo subjetividade. O mesmo aconteceu quando a palavra Psicologia vinha acompanhada por algum indicador que pudesse se relacionar com a temática em questão, como, por exemplo, a conjunção da palavra Psicologia com Vygotsky, Psicologia com Wallon, Psicologia e cognição.

Das 273 produções apresentadas no GT20 no período de 2000 a 2010, o levantamento inicial por palavras-chave nos títulos resultou em 77 produções, distribuídas entre todas as modalidades existentes na ANPEd.

Após essa seleção, Bardin (1977, p. 96) sugere uma leitura flutuante, para um contato maior com o material selecionado. A autora define essa fase como uma atividade que "consiste em estabelecer contacto com os documentos a analisar e em conhecer o texto deixando-o invadir por impressões e orientações". Dessa forma, as informações tornam-se mais precisas. A leitura dos resumos levou à busca de indicadores que revelassem detalhes sobre o conteúdo abordado na produção, para que se confirmasse ou não a escolha feita - ou seja, o texto selecionado aborda de fato a questão da afetividade e sua relação com os processos de ensino e aprendizagem?

Em alguns casos, foi necessária uma "leitura flutuante" do texto completo, pois as informações contidas no resumo não eram suficientes para determinar a utilização da produção em questão. Da mesma forma, tal leitura foi realizada nos casos em que não foi possível o acesso aos resumos. Essa etapa de seleção resultou em 37 produções, que foram lidas na íntegra.

A fase seguinte é denominada por Bardin (1977) de exploração do material e consistiu em um estudo aprofundado do conjunto coletado, lançando mão de procedimentos de categorização. A leitura completa das produções foi acompanhada de fichamento de cada uma. Após esse momento, foram excluídas 13 produções, pois apesar de indicarem no título e no resumo que tratariam da questão de interesse da pesquisa, não traziam contribuições efetivas, pois não abordavam a afetividade de forma direta. Portanto, o tratamento mais detalhado das informações aconteceu com 24 produções. A Tabela 1 mostra a quantidade de produções apresentadas no GT20 no período pesquisado e as selecionadas em cada etapa do processo de busca.

Tabela 1. Total de produções apresentadas no GT20 em relação ao total selecionado em cada etapa do trabalho: pelo título, pelo resumo e pela leitura do texto completo.

\begin{tabular}{|c|c|c|c|c|}
\hline Reunião & $\begin{array}{c}\text { Total de produções } \\
\text { apresentadas no } \\
\text { GT20 }\end{array}$ & $\begin{array}{c}\text { Total de produções } \\
\text { selecionadas por título }\end{array}$ & $\begin{array}{c}\text { Total de produções } \\
\text { selecionadas por } \\
\text { resumo }\end{array}$ & $\begin{array}{l}\text { Total de produções } \\
\text { selecionadas pela } \\
\text { leitura do texto } \\
\text { completo }\end{array}$ \\
\hline $23^{a}-2000$ & 19 & 6 & 2 & 1 \\
\hline $24^{a}-2001$ & 29 & 11 & 6 & 4 \\
\hline $25^{a}-2002$ & 23 & 4 & 3 & 2 \\
\hline $26^{a}-2003$ & 35 & 6 & 4 & 3 \\
\hline $27^{a}-2004$ & 20 & 5 & 4 & 2 \\
\hline $28^{a}-2005$ & 33 & 11 & 4 & 2 \\
\hline $29^{a}-2006$ & 17 & 7 & 1 & 1 \\
\hline $30^{a}-2007$ & 17 & 6 & 2 & 1 \\
\hline $31^{a}-2008$ & 35 & 10 & 6 & 5 \\
\hline $32^{a}-2009$ & 33 & 5 & 3 & 1 \\
\hline $33^{a}-2010$ & 12 & 6 & 2 & 2 \\
\hline TOTAL & 273 & 77 & 37 & 24 \\
\hline
\end{tabular}


Tabela 2. Quantidade de produções apresentadas, por modalidade, no GT20 - Psicologia da Educação, no período de 2000 a 2010 , em relação à quantidade de produções selecionadas, por modalidade, na etapa final, em cada Reunião Anual.

\begin{tabular}{|c|c|c|c|c|c|c|c|c|c|c|}
\hline \multirow{2}{*}{ Reunião } & \multicolumn{5}{|c|}{$\begin{array}{l}\text { Total de produções apresentadas na reunião } \\
\text { do GT20 }\end{array}$} & \multicolumn{5}{|c|}{$\begin{array}{l}\text { Total de produções selecionadas na etapa final } \\
\text { no GT20 }\end{array}$} \\
\hline & $\begin{array}{l}\bar{\Phi} \\
\bar{D} \\
0 \\
0\end{array}$ & 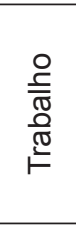 & 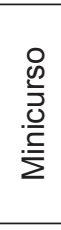 & 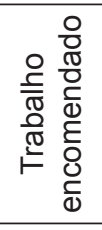 & 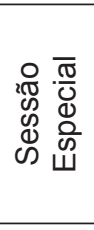 & $\begin{array}{l}\bar{\Phi} \\
\bar{\omega} \\
0 \\
0\end{array}$ & 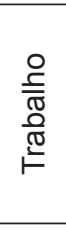 & 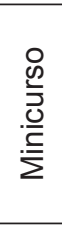 & 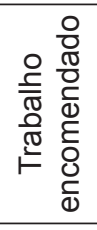 & 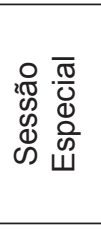 \\
\hline $23^{a}-2000$ & 2 & 14 & 1 & 2 & 0 & 0 & 1 & 0 & 0 & 0 \\
\hline $24^{a}-2001$ & 4 & 13 & 1 & 2 & 9 & 0 & 3 & 0 & 1 & 0 \\
\hline $25^{a}-2002$ & 6 & 6 & 1 & 1 & 9 & 0 & 2 & 0 & 0 & 0 \\
\hline $26^{a}-2003$ & 6 & 13 & 0 & 1 & 15 & 0 & 1 & 0 & 1 & 1 \\
\hline $27^{a}-2004$ & 3 & 13 & 1 & 1 & 2 & 1 & 0 & 1 & 0 & 0 \\
\hline $28^{a}-2005$ & 7 & 23 & 1 & 1 & 1 & 1 & 1 & 0 & 0 & 0 \\
\hline $29^{a}-2006$ & 3 & 11 & 1 & 1 & 1 & 0 & 1 & 0 & 0 & 0 \\
\hline $30^{a}-2007$ & 1 & 11 & 1 & 1 & 3 & 0 & 1 & 0 & 0 & 0 \\
\hline $31^{a}-2008$ & 2 & 15 & 1 & 1 & 16 & 0 & 5 & 0 & 0 & 0 \\
\hline $32^{a}-2009$ & 2 & 12 & 1 & 2 & 16 & 0 & 1 & 0 & 0 & 0 \\
\hline $33^{a}-2010$ & 0 & 10 & 1 & 1 & 0 & 0 & 2 & 0 & 0 & 0 \\
\hline $\begin{array}{l}\text { Total por } \\
\text { modalidade }\end{array}$ & 36 & 141 & 10 & 14 & 72 & 2 & 18 & 1 & 2 & 1 \\
\hline Total geral & \multicolumn{5}{|c|}{273} & \multicolumn{5}{|c|}{24} \\
\hline
\end{tabular}

Como já exposto anteriormente, as produções apresentadas na ANPEd têm modalidades diferentes. Assim, a Tabela 2 mostra o total de produções apresentadas no GT20 - Psicologia da Educação, em cada Reunião Anual, por modalidade, seguida da quantidade final das produções selecionadas também por modalidade.

Antes de iniciar a análise das tabelas apresentadas, é importante destacar algumas particularidades do site da ANPEd. Embora a contagem das produções se refira ao GT Psicologia da Educação, em alguns anos, as Sessões Especiais apareceram como modalidade da Reunião Anual, sem a possibilidade de identificar a qual ou a quais GT(s) se relacionavam. Devido a isso, nos anos de 2001, 2002, 2003, 2008 e 2009 , foram contabilizadas todas as produções des- sas sessões, garantindo assim que não fosse excluído da pesquisa nenhum material que pudesse contribuir para 0 levantamento em questão.

Observando as Tabelas 1 e 2, é possível notar que, das 273 produções apresentadas no GT20 em um período de onze anos, 24 delas abordaram, de alguma maneira, o tema afetividade. Essas 24 produções representam 8,79\% do total apresentado. Com isso, constata-se que a afetividade tem sido explorada por uma significativa parcela dos pesquisadores e, ainda, que a modalidade mais produtiva para a pesquisa foi a dos Trabalhos, na qual os pesquisadores submetem ao evento produções relativas a estudos em conclusão parcial ou final com significativa relevância para a área da Educação. 
Tabela 3. Produções selecionadas por modalidade e total de produções selecionadas por Reunião Anual.

\begin{tabular}{|c|c|c|c|c|c|c|}
\hline \multirow[b]{2}{*}{ Reunião } & \multicolumn{5}{|c|}{ Total de produções selecionadas por modalidade no GT20 } & \multirow{2}{*}{ 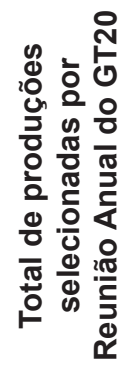 } \\
\hline & 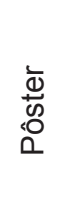 & 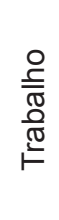 & 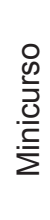 & 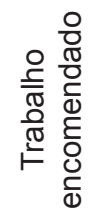 & 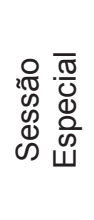 & \\
\hline $23^{a}-2000$ & 0 & 1 & 0 & 0 & 0 & 1 \\
\hline $24^{a}-2001$ & 0 & 3 & 0 & 1 & 0 & 4 \\
\hline $25^{a}-2002$ & 0 & 2 & 0 & 0 & 0 & 2 \\
\hline $26^{a}-2003$ & 0 & 1 & 0 & 1 & 1 & 3 \\
\hline $27^{a}-2004$ & 1 & 0 & 1 & 0 & 0 & 2 \\
\hline $28^{a}-2005$ & 1 & 1 & 0 & 0 & 0 & 2 \\
\hline $29^{a}-2006$ & 0 & 1 & 0 & 0 & 0 & 1 \\
\hline $30^{a}-2007$ & 0 & 1 & 0 & 0 & 0 & 1 \\
\hline $31^{a}-2008$ & 0 & 5 & 0 & 0 & 0 & 5 \\
\hline $32^{a}-2009$ & 0 & 1 & 0 & 0 & 0 & 1 \\
\hline $33^{a}-2010$ & 0 & 2 & 0 & 0 & 0 & 2 \\
\hline $\begin{array}{c}\text { Total por } \\
\text { modalidade }\end{array}$ & 2 & 18 & 1 & 2 & 1 & \\
\hline Total geral & \multicolumn{5}{|c|}{24} & 24 \\
\hline
\end{tabular}

É importante destacar que cada uma das modalidades requer uma estrutura diferente de texto e uma profundidade na abordagem do tema também diferenciada. Dessa forma, na Tabela 2 identificam-se as produções que resultam de pesquisas diversas revelando o interesse de pesquisadores pelo tema, como também se identificam as produções que foram solicitadas pela coordenação do GT20.

Os Pôsteres, Trabalhos e Minicursos que são inscritos pelos pesquisadores e ficam sujeitos à aprovação de cada GT da ANPEd representam $87,5 \%$ do total selecionado para a pesquisa. Destes, $75 \%$ representam as produções originárias da modalidade Trabalhos.

As Sessões Especiais e os Trabalhos Encomendados, que são produções solicitadas aos autores de credibilidade na área da Educação, representaram 12,5\% do material utilizado em nosso estudo.
A partir da análise desses dados, observa-se que tem havido preocupação de diversos autores com o estudo da afetividade e também de temas adjacentes que acabam tratando-a de alguma maneira.

Observa-se, ainda, que os anos de 2001 e 2003 destacaram-se por apresentar produções encomendadas para promover a discussão sobre a questão da afetividade, evidenciando um interesse específico por parte da coordenação do GT20 e de outros GTs.

Em relação às modalidades que implicam em inscrições e aprovações, os anos de 2001 e 2008 foram os que mais contemplaram produções originárias de pesquisa explorando as questões afetivas.

É interessante ressaltar também que, no período em que foi feito o rastreamento das produções - 2000 a 2010 -, em todos os anos, pelo menos uma produção foi selecio- 
nada para a pesquisa por tratar da afetividade de maneira significativa.

$\mathrm{Na}$ Tabela 3 apresentamos, além das modalidades das produções, o total de textos selecionados em cada Reunião Anual, o que permite perceber qual o ano mais produtivo em discussões sobre a afetividade.

No processo de leitura e fichamento das 24 produções selecionadas, a organização feita identificou o título, o nome do(s) autor(es), o objetivo, a metodologia, o referencial teórico em que se baseou, os resultados obtidos e, finalmente, uma apreciação pessoal acerca do conteúdo das mesmas.

Finalizado esse procedimento, iniciou-se a terceira e última etapa de análise, que, segundo Bardin (1977), corresponde ao tratamento dos resultados obtidos para que se realize a interpretação, envolvendo a reflexão e inferências. Nesse movimento de categorização do material coletado, a organização buscou o referencial teórico em que as produções foram fundamentadas, para que se tivesse uma visão geral de como a afetividade vem sendo discutida pelos pesquisadores em educação atualmente.

\section{A afetividade e suas abordagens}

Dentre as 24 produções selecionadas, sete foram discutidas a partir das contribuições de Wallon (Almeida, 2001; Dourado \& Prandini, 2001; Groppo \& Almeida, 2008; Mahoney \& Almeida, 2004a, 2005; Silva, 2005; Sugahara \& Sousa, 2010), assumindo a afetividade como um dos domínios que compõe o ser humano, sendo este formado pela relação indissociável existente entre os domínios afetivo, cognitivo e motor, constituindo o que Wallon denominou de pessoa. Os textos exploraram uma das maiores contribuições da teoria de Wallon para o estudo da afetividade: a ideia de que esta se refere a um conjunto que compreende emoções, sentimentos e paixão e que sofre transformações qualitativas ao longo do desenvolvimento dos indivíduos.

Mahoney (2004, p. 17), a partir da perspectiva walloniana, nos ajuda a compreender a afetividade como responsável

pelas emoções, pelos sentimentos e pela paixão, que são sinalizadores de como o ser humano é afetado pelo mundo interno e externo. Essa condição de ser afetado pelo mundo estimula tanto os movimentos do corpo como a atividade mental. São recursos de sociabilidade, de comunicação, exercendo atração sobre o outro com o apoio do ato motor.

Segundo Wallon, as emoções são de caráter fundamentalmente orgânico, seguidas de transformações físicas, como aumento de batimentos cardíacos, tremedeira e palidez. Já os sentimentos são resultados das transformações qualitativas sofridas pelas emoções e refletem o surgimento da capacidade de representação - a inserção no mundo simbólico. A paixão pressupõe a capacidade de autocontrole visando ao domínio de uma dada situação. Enquanto a paixão é mais encoberta, mais duradoura, mais intensa, mais focada, a emoção é visível, fugaz, também intensa, mas sem controle. O sentimento, por sua vez, em função do desenvolvimento da capacidade simbólica, perde seu recurso de visibilidade e é mais duradouro, menos intenso e mais controlado (Mahoney, 2004).

Dentre as sete produções que discutiram a afetividade sob a perspectiva de Wallon, uma delas tratava-se de um minicurso (Mahoney \& Almeida, 2004a), apresentando uma estrutura diferente das demais.

Duas produções abordaram a afetividade segundo as contribuições de Wallon e Vygotsky (Tassoni, 2000; Tassoni \& Leite, 2010). Segundo os autores desses dois trabalhos, Wallon e Vygotsky comungam de muitas ideias quando o tema é a afetividade. Dentre elas, destacaram o caráter fundamentalmente social da dimensão afetiva, a ideia de transformação da afetividade e também a sua indissociável relação com o domínio cognitivo. Exploraram a afetividade na relação professor-aluno como um aspecto que marca a relação deste com o objeto de conhecimento.

Das 24 produções, cinco basearam-se na Psicanálise (Archangelo, Peres, Cunha, \& Amon, 2008; Farias, 2008; Oyama, 2008; Souza, 2002, 2003), de maneira especial, mas não exclusiva, nas contribuições de Freud. Nestas, a afetividade foi discutida segundo alguns mecanismos psicanalíticos, como, por exemplo, a identificação, a transferência, o luto, a frustração, entre outros. Os autores desses cinco trabalhos discutiram os aspectos afetivos com enfoques distintos, referindo-se, por exemplo: à transferência que o aluno faz para os professores das expectativas e do respeito que nutrem pelos pais; ao apelo emocional feito pelo professor para garantir sua autoridade, de modo a influenciar o comportamento dos alunos em diversas situações (quando o professor fala que ficou triste, que não gosta mais das crianças etc.); às discussões sobre o equilíbrio dos domínios da razão e da paixão, mostrando como a paixão mobiliza os sujeitos; aos sentimentos de angústia e ódio, mostrando como a dimensão afetiva afeta as relações em sala de aula, mais especificamente, na relação professor-aluno; aos mecanismos de identificação, transferência, projeção e luto para abordar a dimensão afetiva e sua presença na sala de aula; à repressão, frustração, transferência e sedução presentes na fala e na escuta dos professores em sala de aula.

As produções que se basearam na Teoria Psicanalítica abordaram os mecanismos que os homens utilizam para se defender do sofrimento, das situações que os afligem, sendo assim, a subjetividade foi o aspecto central de algumas dessas discussões. É a forma como as pessoas lidam com as diferentes situações (ingresso na escola, forma de controlar alunos pautada em apelos emocionais etc.) que possui, impreterivelmente, estreita relação com os sentimentos e as emoções que perpassam o ambiente escolar.

Segundo Souza (2003), Freud, assim como outros autores, defende que o homem não é unicamente constituído pela razão.

Freud está inscrito no grupo daqueles que relevam a paixão e propõe a sua escuta. Ele releva o humano como marcado pela pulsão entendida como expressão do somato e do 
psíquico, do corpo e da representação. O corpo constituise na fonte das excitações, às quais as representações se agregam, permitindo-nos assim o acesso aos afetos e às emoções e explicitando o plano singular e o coletivo (Souza, 2003, p. 8).

Percebe-se nessa afirmação a presença de uma "concepção mais integradora" do homem, em que aspectos cognitivos estão intrinsecamente associados a outros aspectos que o constituem.

É relevante destacar que a Psicanálise surge como forma de romper com a concepção que se tinha de conhecimento científico no século XIX. Afinal, tem como foco de estudo a subjetividade.

Uma das produções baseada no enfoque psicanalítico refere-se a um trabalho encomendado, o que indica a sua relevância para a educação (Souza, 2003).

Houve ainda uma produção (Magiolino \& Smolka, 2009) que fez uma discussão entre os pressupostos de Vygotsky e Freud no que diz respeito ao afeto e à emoção. As autoras afirmaram que o estudo dos sentimentos e emoções, segundo Vygotsky, e das pulsões, a partir de Freud, caracterizam-se como o capítulo mais obscuro da Psicologia. Destacaram que estudar o afeto e a emoção segundo a perspectiva desses dois autores é um desafio, pois esses aspectos, além de perpassarem toda a teoria de Vygotsky, são explorados a partir da interlocução entre muitos autores e fazem parte de um estudo apresentado em uma obra inacabada. Já em Freud, o afeto não é um conceito desse autor, no entanto, é possível perceber em suas teorias representações de afeto em diversas situações e em muitos sentidos, atrelado, por exemplo, às pulsões sexuais.

As autoras afirmaram ainda que, apesar das grandes diferenças teóricas entre Vygotsky e Freud, ambos comungam da ideia de uma concepção monista de ser humano - razão e emoção como interdependentes.

Das 24 produções, apenas uma abordou a questão da afetividade sob a perspectiva behaviorista (Moroz e cols., 2002), segundo as contribuições de Skinner, afirmando que tudo o que se passa sob a pele humana é uma construção social, incluindo os sentimentos, as percepções, os estados e o pensamento.

Moroz e cols. (2002) afirmam que, segundo Skinner, não temos acesso direto ao que se passa sob a pele do indivíduo. É através do comportamento - respostas colaterais públicas emitidas pelo indivíduo - que se pode compreender o que está encoberto. Para os autores, Skinner enfatiza que os sentimentos e as emoções são nomeados pelos indivíduos a partir da convivência social, pois são metáforas transferidas do público para o privado.

Ainda segundo os autores, Skinner faz uma diferenciação entre eventos públicos - que podem ser descritos por mais de uma pessoa - e eventos privados - que só podem ser relatados pelo sujeito individualmente, como, por exemplo, o pensamento. Assim, os eventos públicos são estudados por meio dos comportamentos observáveis; já os eventos privados só são acessíveis mediante os relatos verbais do sujeito envolvido.

Apesar de o Behaviorismo ser visto como uma corrente de estudos reducionista, o Behaviorismo Radical, abordado na produção selecionada, defende o caráter social daquilo que está sob a pele dos indivíduos (Moroz e cols., 2002). A afetividade, então, pode ser vista nas discussões sobre os sentimentos que a produção em questão realiza. Sua manifestação é vista como uma resposta do indivíduo aos eventos (estímulos) públicos.

Ainda buscando identificar em que perspectivas teóricas os estudos sobre a afetividade têm sido abordados e discutidos, a coleta de dados apontou duas produções que abordaram a afetividade na perspectiva construtivista, pautada nas contribuições de Piaget (Silva, 2004; Uller \& Rosso, 2006). Ambas as produções destacam que, segundo esse teórico, o conhecimento é uma construção que se dá a partir da relação que se estabelece entre sujeito e objeto. E é nessa discussão acerca do conhecimento e da inteligência que Piaget traz sua contribuição a respeito da afetividade. Os autores afirmam que, para Piaget, afetividade e inteligência se relacionam de forma indissociável, apesar de serem de naturezas diferentes, pois a afetividade sempre atua no funcionamento do pensamento, podendo interferir nos processos desenvolvimento da inteligência.

Nessas produções, a afetividade foi discutida sob o pressuposto de que, para a construção do conhecimento, o sujeito deve se envolver com o objeto de estudo, atribuindo significações a ele (objeto). É nesse momento que se percebe a articulação entre o domínio afetivo e o cognitivo. A afetividade é considerada como o combustível que leva o motor a funcionar; ou seja, traz a possibilidade de acelerar ou atrasar os processos de desenvolvimento da inteligência.

Em uma das produções houve grande destaque para a questão da motivação (Silva, 2004). Nela evidenciou-se a importância da criança envolver-se com o objeto de estudo, atribuir significado a ele, motivar-se, para que a aprendizagem ocorra de forma efetiva. Encontramos uma discussão acerca da relação entre afetividade e aprendizagem. Nessa perspectiva também se defende uma visão integradora de ser humano, um todo composto por razão e emoção; um ser em que os domínios afetivo e cognitivo são interdependentes.

Das 24 produções selecionadas, apenas uma trouxe a afetividade discutida sob a perspectiva da abordagem centrada na pessoa, pautada nas ideias desenvolvidas por Carl Rogers (Duek, 2007). Tal produção abordou a afetividade no âmbito dos sentimentos dos profissionais de educação. Defendeu que os professores devem ter um espaço em que possam expor seus sentimentos de amor, raiva, angústia, a fim de refletirem sobre eles, identificarem que sentimentos têm em relação aos seus alunos e possam ressignificar suas experiências. Segundo Duek (2007), para Rogers, a aprendizagem passa pela afetividade. Portanto, é fundamental que se dê vazão aos sentimentos pessoais, pois estes interferem de maneira efetiva no processo de ensino-aprendizagem. 
Ainda trabalhando na categorização das produções selecionadas de acordo com os referenciais teóricos que discutem a afetividade, há uma que abordou a afetividade em uma perspectiva filosófica, fundamentada em Deleuze e Foucault (Farina, 2001).

Nessa produção, a afetividade é discutida em sua relação com a Arte. A autora explora a atribuição de sentido às obras de arte não só por saber sua importância, admirar seu ineditismo ou sua genialidade, mas afirma a importância de construir significados pelas sensações que a obra contém. Desse modo, Farina (2001) afirma que os afetos são a matéria-prima da obra que se transforma na peça produzida pelo artista. $O$ texto traz, também, uma estreita relação entre pensar e sentir. Baseando-se em Foucault, tal relação se mostra na ideia de que pensar é sentir com a imaginação.

Ainda dentre as 24 produções, duas basearam-se nos estudos de Maturana (Dorneles, 2003; Lopes, 2008). Na realidade, os textos também fazem referência a outros autores como Mafessoli, Balandier, Morin e Latour, mas centram suas ideias nas contribuições do biólogo chileno Maturana.

Uma dessas duas produções foi uma Sessão Especial (Dorneles, 2003), indicando o interesse da coordenação do GT e da organização da ANPEd como um todo em promover/ampliar as discussões sobre a afetividade.

Ambas as produções afirmam que Maturana traz diversas contribuições para o estudo das emoções, classificando-as como o fundamento da razão. Busca romper com a dualidade entre razão e emoção, afirmando que "toda racionalidade seria, ela própria, o emergente de um emocionar" (Maturana citado por Lopes, 2008, p. 6). Para os autores, Maturana destaca o aspecto corpóreo da emoção e também afirma que as ações do homem decorrem da emoção, alertando que, para compreender as ações do ser humano, é preciso conhecer a emoção e, para conhecer a emoção, é preciso olhar para a ação.

Segundo Dorneles (2003) e Lopes (2008), Maturana também vem a contribuir para que se tenha uma visão monista do ser humano, na qual razão e emoção não são polos distintos, e sim dois fatores que inegavelmente se relacionam na constituição do homem.

Dentre as 24 produções estudadas, apenas uma se fundamentou nas ideias adaptadas ${ }^{2}$ de Abric, o qual traz uma abordagem estrutural das representações. "Na perspectiva de Abric, a representação é vista como um sistema sociocognitivo particular composto de dois sub-sistemas: o núcleo central e o sistema periférico" (Mazzoti, 2003, p. 3).

Esse texto não abordou especificamente a afetividade, mas as representações dos professores a respeito do "fracasso escolar". Dentre essas representações, os sentimentos de tristeza, fracasso, desmotivação estão presentes, mas não constituem o foco da autora.

Uma das produções encontradas foi um Trabalho Encomendado. O autor - Fernando Rey (2001) - abordou a questão da subjetividade, afirmando que não se encara a

2 É a própria autora do texto que afirma que fundamentou seu trabalho em uma "adaptação da abordagem estrutural das representações proposta por Abric" (Mazzoti, 2003, p. 3). subjetividade individual como algo distinto da subjetividade social, pois nenhuma atividade humana pode ser isolada do conjunto de significações produzidas no mundo em que vivemos (mundo histórico e social).

Rey (2001) citou a instituição escolar considerando-a como parte da sociedade e não como uma instituição independente dos processos de produção de sentido que se desenvolvem na sociedade. Ainda pautado na ideia de encarar tanto a escola como a sociedade e o homem em um conjunto que está indissociavelmente relacionado, o autor defendeu a superação de dicotomias como subjetividade individual e subjetividade coletiva, afetividade e cognição, psicologia e educação. É a partir dessas ideias que seu trabalho se destacou como um estudo atual acerca da afetividade e sua relação com os processos de ensino e aprendizagem.

A Tabela 4 permite que se tenha uma visão geral das perspectivas teóricas em que a afetividade foi abordada nas 24 produções selecionadas no período de 2000 a 2010 no GT20 - Psicologia da Educação.

Tabela 4. Perspectivas teóricas segundo as quais a afetividade foi abordada nas produções selecionadas.

\begin{tabular}{|l|c|}
\hline $\begin{array}{c}\text { Perspectiva teórica } \\
\text { (autores) }\end{array}$ & $\begin{array}{c}\text { Número de textos } \\
\text { selecionados }\end{array}$ \\
\hline Wallon & 2 \\
\hline Wallon e Vygotsky & 5 \\
\hline Freud & 1 \\
\hline Freud e Vygotsky & 1 \\
\hline Skinner & 2 \\
\hline Piaget & 1 \\
\hline Carl Rogers & 1 \\
\hline Foucault & 24 \\
\hline Maturana & 1 \\
\hline Abric & 1 \\
\hline Fernando Rey & 24 \\
\hline Total & 1 \\
\hline
\end{tabular}

Observa-se que a maioria das produções foi discutida à luz do referencial walloniano. Elas representaram 29,19\% do total. Freud vem em segundo lugar, sendo representado em $20,83 \%$ dos textos. Esses números demonstram os teóricos que mais apareceram nas discussões sobre a afetividade. 
É interessante ressaltar que três produções promoveram o diálogo entre teóricos: Wallon e Vygotsky (Tassoni, 2000; Tassoni \& Leite, 2010) e Freud e Vygostsky (Magiolino \& Smolka, 2009). Esses trabalhos demonstraram um esforço dos autores em abordar a afetividade evidenciando aproximações e afastamentos entre teóricos diferentes.

Outro fator relevante observado diz respeito à quantidade de produções que tratam da afetividade - dos afetos, dos sentimentos e emoções - como tema central. Doze textos, o que representa $50 \%$ do material estudado, abordam as discussões sobre afetividade como tema central. As outras doze produções exploram outros conceitos como temas centrais - subjetividade, relação professor-aluno, fracasso escolar, motivação, constituição da pessoa - mas todas, de alguma forma, contribuem para as discussões sobre os fenômenos afetivos.

A partir da construção desse panorama geral dos referenciais teóricos em que a afetividade foi abordada, discute-se agora a segunda parte do problema que norteia a pesquisa: em que medida tais estudos contemplam as influências entre os aspectos afetivos e os processos de ensino e aprendizagem?

Depois de analisar e fichar todas as produções, foi possível constatar que 21 delas trataram da afetividade em uma relação indissociável com os processos de ensino e aprendizagem, o que representa $83,33 \%$ dos textos lidos 3 . Algumas produções abordaram essa relação de forma explícita e com discussões fundamentadas a respeito do tema. Outras apenas citaram essa interdependência ou permitiram que ela fosse inferida de acordo com o conteúdo de seu texto. Apenas em três produções não foram feitas considerações acerca da relação entre o domínio afetivo e os processos relacionados ao ensino e aprendizagem.

Trabalhando com o material selecionado, foi possível identificar, portanto, que muitas produções trataram a relação afetividade e os processos de ensino e aprendizagem, nos levando a pensar que tal discussão tem ganhado espaço no cenário acadêmico. Ainda assim, muitas vezes aparecendo apenas citada em poucas linhas, encontradas na introdução ou nas considerações finais do texto, constituindo-se mais como uma alusão do que propriamente um assunto a ser discutido. Observamos que as relações entre afetividade e aprendizagem têm sido tomadas como ponto de partida e/ou chegada para debater diferentes temáticas, como fracasso escolar, motivação, representação social, relação professor-aluno etc. Temos como hipótese que tal questão pode se relacionar às diferentes maneiras de se compreender e conceituar os fenômenos afetivos. Portanto, tomar a afetividade como objeto de investigação envolve uma significativa complexidade conceitual e de interpretação.

Nas produções selecionadas, a relação entre os domínios afetivo e cognitivo vem citada por meio de diversas denominações: afetividade-aprendizagem, afeto-cognição, razão-emoção, razão-paixão e concepção monista de ser

3 É necessário destacar que a maneira de se referir à afetividade e aos processos de ensino e aprendizagem variou de acordo com o referencial teórico utilizado pelos autores do texto. humano. Essas variações acontecem devido à diferença de referencial teórico que fundamenta as produções. Isso não descaracteriza o debate que, em sua maioria, direciona sempre para a indissocialidade desses aspectos.

Mahoney e Almeida (2000, 2004b, 2007) muito têm contribuído para a discussão entre afetividade e aprendizagem, realizando estudos, fundamentados em Wallon, que aprofundam a compreensão do papel da afetividade na vida psíquica e no processo de ensino e aprendizagem. As pesquisas orientadas por elas avançam em elaborações teóricas acerca dos pressupostos wallonianos, bem como em relação à discussão da afetividade como porta de acesso ao conhecimento. Foram desenvolvidas tanto com professores como com alunos, de diferentes níveis de ensino e diferentes cenários de aprendizagem, identificando e explorando as situações indutoras de sentimentos diversos, possibilitando "extrair direções para tornar mais proveitoso e satisfatório o processo de ensino-aprendizagem" (Mahoney \& Almeida, 2007, p. 19).

$\mathrm{Na}$ mesma direção, Leite e cols. (2006), Leite e Tassoni (2002), Leite e Higa (2011) vêm desenvolvendo estudos que buscam identificar o papel da dimensão afetiva "no planejamento e desenvolvimento das práticas pedagógicas desenvolvidas pelo professor, envolvendo objetivos de ensino, organização dos conteúdos, respeito ao repertório de entrada dos alunos, atividades de ensino desenvolvidas em sala de aula, além das práticas de avaliação" (Leite e cols., 2006, p.8). As pesquisas exploram, em linhas gerais, a relação entre a afetividade e a mediação pedagógica do professor, bem como a afetividade como constitutiva dos movimentos de aproximação e de afastamento dos alunos como os diferentes objetos de conhecimento.

\section{Lendo nas entrelinhas}

Ao longo de toda a pesquisa, fomos percebendo, além do conteúdo manifesto, algumas situações que nos trouxeram elementos para reflexão.

Desde a primeira etapa de coleta de dados, notamos que a palavra-chave mais produtiva na busca foi a subjetividade. Muitas produções a trazem como tema principal. Isso reforça o espaço que a subjetividade vem ganhando nas discussões a respeito da educação e também nas discussões que tratam da constituição do homem. A subjetividade refere-se aos sentidos atribuídos, tanto individual como socialmente, aos diversos contextos, às situações e às experiências vividas. Nesse sentido, envolve vários aspectos, inclusive as emoções.

Apesar do número significativo de produções que continham a palavra-chave subjetividade, a maioria delas não atendia aos problemas de nossa pesquisa, enveredando-se para outros campos de estudo. Por essa razão, foram descartadas conforme as justificativas já apresentadas anteriormente.

Analisando ainda a produtividade das palavras-chave usadas na pesquisa, constatamos que a menos produtiva foi 
a expressão mediação pedagógica; nenhum trabalho foi encontrado especificamente com essa combinação de palavras.

Consideramos oportuno ressaltar que o conceito de mediação cunhado por Vygotsky corresponde à ideia de um elo intermediário na relação sujeito-objeto. Nesse sentido, tal conceito explora o papel do outro como central para os processos de aprendizagem. Embora Vygotsky não tenha sido um autor muito explorado nas discussões sobre a afetividade no GT-20 Psicologia da Educação, trata-se de um teórico que contribuiu de forma fundamental para os estudos sobre o desenvolvimento das emoções humanas e para romper com a visão dualista da época que separava razão e emoção. Nessa direção, o conceito de mediação é um dos conceitos vigotskianos que envolve aspectos cognitivos e afetivos, pois, ao evidenciar o papel das relações entre as pessoas como central para a aprendizagem, abre possibilidades para se discutir a natureza dessas relações. Oliveira, aprofundando os pressupostos vigotskianos, afirma que as relações interpessoais são interações "densas, mediadas simbolicamente, e não trocas mecânicas limitadas a um patamar meramente intelectual" (Oliveira, 1992, p. 80).

Apoiados em Vygotsky, Tassoni e Leite (2011, p. 83) destacam que

considerando o professor um dos mediadores na sala de aula, suas ações têm por objetivo a aprendizagem do aluno. Nessas ações mediadoras, o aluno entra em contato com modos de pensar, agir e sentir em relação ao conhecimento envolvido e a situação em si. Nessa dinâmica, a forma como o aluno significa a ação do professor revela uma atitude afetiva.

As pesquisas desenvolvidas por Leite e cols. (2006) vêm apontando que a qualidade da mediação vivenciada em sala de aula influencia a qualidade da relação estabelecida entre os alunos e os diversos objetos de conhecimento.

Certamente, os dados da pesquisa apontaram que o tema da afetividade tem conquistado seu espaço nas discussões educacionais. Tanto que, em 2001 e em 2003, foram encomendados pelos coordenadores do GT20 da ANPEd produções que discutiram essa temática. Destacamos ainda que, em 2003, além do Trabalho Encomendado, a Sessão Especial também abordou a questão da afetividade, evidenciando um avanço importante. Mesmo assim, ressaltamos que ainda há muito que se discutir a respeito da interdependência entre os domínios afetivo e cognitivo nos ambientes de aprendizagem, de maneira especial na escola.

Observamos que, no ano de 2008, as discussões sobre a afetividade foram mais produtivas, sendo que, dos 24 trabalhos selecionados para a etapa da descrição analítica, cinco advém da Reunião Anual ocorrida nesse ano. Isso sugere, segundo Leite e cols. (2006, p. 17) que

a partir da ampliação dos conhecimentos sobre a emoção e seus complexos processos de constituição, o conceito de homem centrado apenas na sua dimensão racional, típico da visão cartesiana, vem sendo revisto, em direção a uma concepção monista de constituição de ser humano, em que afetividade e cognição passam a ser interpretadas como dimensões indissociáveis do mesmo processo, não sendo mais aceitável analisá-las isoladamente.

Os dados nos revelaram a notoriedade que o tema foi ganhando ao longo dos anos. A necessidade de pesquisá-lo demonstra sua importância para a compreensão da constituição do homem, como também para a educação.

As 24 produções selecionadas utilizaram, essencialmente, dez teóricos diferentes para apoiar suas pesquisas. Isso mostra que as discussões sobre a afetividade vêm sendo realizadas por autores de concepções teóricas distintas, comprovando a importância do papel desempenhado por ela no desenvolvimento do homem. Como já apontado, Wallon e Freud foram os teóricos mais citados.

Outro aspecto a se destacar diz respeito ao que se entende pela relação afetividade e aprendizagem, pois em alguns trabalhos os autores não abordaram explicitamente essa relação, mas trouxeram informações e fizeram constatações que evidenciaram a interdependência desses aspectos. Como já apontado, há ainda lacunas nessa articulação entre os domínios. Os trabalhos que tratam da representação dos professores em relação aos alunos, dos alunos em relação ao professor, dos alunos e professores em relação à escola etc. discutem claramente sobre essa relação indissociável, mas pouco enfocam teoricamente essa questão. Considerando essa afirmação, deixamos uma pergunta a ser respondida: as representações marcam os processos de avaliação, de ensino e de aprendizagem; como se discutir, então, as influências da afetividade nessas representações?

Conseguimos, por meio desta pesquisa, responder aos dois problemas que impulsionaram nossos estudos. Mas o mais interessante é que a terminamos com outros fervilhando. É essa infinitude do conhecimento que move o mundo acadêmico na busca por novas produções científicas, e isso, para quem inicia e para quem já está inserido no universo da pesquisa, é encantador.

\section{Referências}

Almeida, A. R. S. (2001). O que é afetividade? Reflexões para um conceito. Anais da XXIV Reunião Anual da ANPEd. Caxambu, MG.

Archangelo, A., Peres, B. A., Cunha, J. E. B., \& Amon, M. C. I. (2008). Os aspectos afetivos no processo de aprendizagem da Matemática e da Física. Anais da XXXI Reunião Anual da ANPEd. Caxambu, MG.

Bardin, L. (1977). Análise de Conteúdo. Lisboa: Edições 70.

Dorneles, M. A. (2003). Disposições ético-estético-afetivas e desafios teórico-metodológicos na Pesquisa em Educação. Anais da XXVI Reunião Anual da ANPEd. Poços de Caldas, MG. 
Dourado, I. C. P., \& Prandini, R. C. A. R. (2001). Henri Wallon: Psicologia e Educação. Anais da XXIV Reunião Anual da ANPEd. Caxambu, MG.

Duek, V. P. (2007). Relação professor-aluno: a propósito do outro diferente. Anais da XXX Reunião Anual da ANPEd. Caxambu, MG.

Farias, M. L. S. O. (2008). Afeto: nos fios dos bastidores da sala de aula. Anais da XXXI Reunião Anual da ANPEd. Caxambu, MG.

Farina, C. (2001). Pedagogia dos afetamentos. Anais da XXIV Reunião Anual da ANPEd. Caxambu, MG.

Groppo, C., \& Almeida, L. R. (2008). Passagem de professor a professor coordenador: a dimensão afetiva em foco. Anais da XXXI Reunião Anual da ANPEd. Caxambu, MG.

Leite, S. A. S. e cols. (2006). Afetividade e Práticas Pedagógicas. São Paulo: Casa do Psicólogo.

Leite, S. A. S., \& Higa, S. E. L. (2011). Aproximação e Afastamento na relação entre crianças e as práticas de leitura: o papel da mediação pedagógica do professor. Em M. I. S. Leme \& P. S. Oliveira (Orgs.), Proximidade e Distanciamento_(pp. 139-160). São Paulo: Casa do Psicólogo

Leite, S. A. S., \& Tassoni, E. C. M. (2002). Afetividade em sala de aula: as condições do ensino e a mediação do professor. Em R. G. Azzi \& A. M. F. A. Sadalla (Orgs.), Psicologia e Formação Docente: desafios e conversas (pp. 113-141). São Paulo: Casa do Psicólogo.

Lopes, E. S. (2008, outubro). O emocionar de um professor. Anais da XXI Reunião Anual da ANPEd. Caxambu, MG.

Magiolino, L. L. S., \& Smolka, A. L. B. (2009). Afeto e emoção no diálogo de Vygotsky com Freud: apontamentos para a discussão contemporânea. Anais da XXXII Reunião Anual da ANPEd. Caxambu, MG.

Mahoney, A. A. (2004). A constituição da pessoa: desenvolvimento e aprendizagem. Em A. A. Mahoney \& L. R. Almeida (Orgs.), A constituição da pessoa na proposta de Henri Wallon (pp. 13-24). São Paulo: Edições Loyola.

Mahoney, A. A., \& Almeida, L. R. (2000). Henri Wallon. São Paulo: Edições Loyola.

Mahoney, A. A., \& Almeida, L. R. (2004a). Afetividade e processo ensino-aprendizagem: contribuições de Henri Wallon. Anais da XXVII Reunião Anual da ANPEd. Caxambu, MG.

Mahoney, A. A., \& Almeida, L. R. (Orgs.). (2004b). A constituição da pessoa na proposta de Henri Wallon. São Paulo: Edições Loyola.

Mahoney, A. A., \& Almeida, L. R. (2005). Sentimentos e emoções: um estudo com professores do ensino superior. Anais da XXVIII Reunião Anual da ANPEd. Caxambu, MG.
Mahoney, A. A., \& Almeida, L. R. (Orgs.). (2007). Afetividade e Aprendizagem: contribuições de Henri Wallon. São Paulo: Edições Loyola.

Mazzotti, A. J. A. (2003). Fracasso Escolar: representações de professores e de alunos repetentes. Anais da XXVI Reunião Anual da ANPEd. Poços de Caldas, MG.

Moroz, M., Rubano, D. R., Maurutto, A., Lucci, M. A., Gianfaldoni, M. H. T. A., Utida, H. H. e cols. (2002). Subjetividade: a interpretação do behaviorismo radical. Anais da XXV Reunião Anual da ANPEd. Caxambu, MG.

Oliveira, M. O. (1992). O problema da afetividade em Vygotsky. Em Y. de La Taille, M. K. de Oliveira \& H. Dantas (Orgs.), Piaget, Vygotsky Wallon: teorias psicogenéticas em discussão. São Paulo: Summus.

Oyama, D. K. (2008). Angústia e Ódio na relação professor-aluno. Anais da XXXI Reunião Anual da ANPEd. Caxambu, MG.

Rey, F. L. G. (2001). A pesquisa e o tema da subjetividade em educação. Anais da XXIV Reunião Anual da ANPEd. Caxambu, MG.

Silva, A. M. T. B. (2004). O lúdico na relação ensino aprendizagem das ciências: resignificando a motivação. Anais da XXVII Reunião Anual da ANPEd. Caxambu, MG.

Silva, A. R. C. (2005). Sentimentos e emoções: um estudo com professores e alunos do curso de medicina veterinária. Anais da XXVIII Reunião Anual da ANPEd. Caxambu, MG.

Silva, L. N. D., \& Peixoto, A. J. (Orgs). (2000). Anuário-2000 Psicologia: análise e crítica da prática educacional. Caxambu, MG: ANPEd.

Souza, E. C. L. L. (2002). Relação professor-aluno: subjetividade e objetividade na sala de aula. Anais da XXV Reunião Anual da ANPEd. Caxambu, MG.

Souza, M. (2003). Fios e furos: a trama da subjetividade e a educação. Anais da XXVI Reunião Anual da ANPEd. Poços de Caldas, MG.

Sugahara, L. Y., \& Sousa, C. P. (2010). A dimensão afetiva nas representações sociais sobre o trabalho docente. Anais da XXXIII Reunião Anual da ANPEd. Caxambu, MG.

Tassoni, E. C. M. (2000). Afetividade e aprendizagem: a relação professor-aluno. Anais da XXIII Reunião Anual da ANPEd. Caxambu, MG.

Tassoni, E. C. M., \& Leite, S. A. S. (2010). A relação afeto, cognição e práticas pedagógicas. Anais da XXXIII Reunião Anual da ANPEd. Caxambu, MG.

Tassoni, E. C. M., \& Leite, S. A. S. (2011). Um estudo sobre emoções e sentimentos na aprendizagem escolar. Comunicações, 18(2), 79-91. Recuperado: 19 Jul. 2012. Disponível: https://www. 
metodista.br/revistas/revistas-unimep/index.php/comunicacao/ article/view/933
Uller, W., \& Rosso, A. J. (2006). Interação da afetividade com a cognição no ensino médio. Anais da XXIX Reunião Anual da ANPEd. Caxambu, MG.

Recebido em: 25/11/11

Reformulado em: 26/07/12

Aprovado em: 25/10/12

\section{Sobre os autores}

Elvira Cristina Martins Tassoni (cristinatassoni@puc-campinas.edu.br) Docente do Programa de Pós-Graduação em Educação da PUC-Campinas Endereço: Rua Profa Dea E. Carvalho, 1415, casa 2. Gramado. CEP: 13101-664. Campinas, São Paulo.

Angélica Niero Mendes dos Santos (angel_niero@hotmail.com)

Graduanda do curso de Pedagogia da PUC-Campinas. Bolsista FAPIC/Reitoria de IC

Endereço: Rua: Alberto da Costa, 560 Jardim Paulista. CEP: 13.208-550. Jundiaí, São Paulo.

Manuscrito derivado de pesquisa de Iniciação Científica financiada pela PUC-Campinas 